\title{
Percepções e expectativas sobre a maternidade de gestantes que vivem com HIV
}

\section{Perceptions and expectations about motherhood of pregnant women living with HIV}

\author{
Floriacy Stabnow Santos ${ }^{1 *}$, Milena da Silva Soares ${ }^{1}$, Janainna Ferreira e Silva ${ }^{1}$, Romila Martins \\ de Moura Stabnow Santos ${ }^{1}$, Pedro Mário Lemos da Silva ${ }^{5}$, Lívia Maia Pascoal ${ }^{1}$, Iolanda Graepp \\ Fontoura $^{1}$, Marcelino Santos Neto ${ }^{1}$
}

\begin{abstract}
RESUMO
Objetivou-se identificar as percepções das gestantes que vivem com o HIV sobre a maternidade e conhecer as expectativas e os sentimentos vivenciados por essas mulheres. Pesquisa descritiva, documental, qualitativa, com a participação de 17 gestantes soropositivas para o HIV, atendidas no Serviço de Atendimento Especializado em HIV/aids do Hospital Regional Materno Infantil de ImperatrizMA realizada entre setembro de 2019 e julho de 2020. Pesquisa aprovada pelo Comitê de Ética em Pesquisa da Universidade Federal do Maranhão sob parecer 2.496.047. As falas das participantes foram gravadas e analisadas segundo a análise do conteúdo e encontrou-se quatro categorias: Sentimentos vivenciados ao diagnóstico do HIV e perspectivas para o futuro; Sentimentos relacionados a gestação no contexto do HIV; Esperanças e expectativas com o futuro do filho; Sensação de impotência diante da impossibilidade de amamentar. Para algumas a descoberta do diagnóstico de soropositividade gerou sentimentos de medo e raiva, algumas se decidiram pela gravidez e para outras a gravidez não foi planejada. Percebeu-se a importância da equipe multidisciplinar para o processo de adaptação da gestante no seu contexto, principalmente no momento de pré-natal.
\end{abstract}

Palavras-chave: Gestantes; Experiências Adversas; Cuidado pré-natal; Cuidado de enfermagem. Sorodiagnóstico de HIV;

\begin{abstract}
This study aimed to identify the perceptions of pregnant women living with HIV about motherhood and to know the expectations and feelings experienced by these women. Descriptive, documentary, qualitative research, with the participation of 17 HIV-positive pregnant women, assisted in the Specialized HIV/AIDS Care Service of the Regional Maternal And Child Hospital of Imperatriz-MA held between September 2019 and July 2020. Research approved by the Research Ethics Committee of the Federal University of Maranhão under opinion 2,496,047. The participants' statements were recorded and analyzed according to content analysis and four categories were found: Feelings experienced at HIV diagnosis and perspectives for the future; Feelings related to pregnancy in the context of HIV; Hopes and expectations for the future of the child; Feeling of helplessness in the face of the impossibility of breastfeeding. For some, the discovery of the diagnosis of seropositivity generated feelings of fear and anger, some decided by pregnancy and for others the pregnancy was not planned. The importance of the
\end{abstract}

\footnotetext{
${ }^{1}$ Universidade Federal do Maranhão. *E-mail: floriacy.stabnow @ ufma.br
} 
multidisciplinary team was perceived for the process of adaptation of the pregnant woman in its context, especially at the time of prenatal care.

Keywords: Pregnant women; Adverse Experiences; Prenatal care; Nursing care. HIV serodiagnosis;

\section{INTRODUÇÃO}

A atual situação do Brasil e do mundo em relação a Síndrome da Imunodeficiência Humana (HIV) ainda é muito grave, pois essa doença é considerada um problema de saúde pública. O HIV no contexto social se torna ainda mais preocupante com o acentuado número de casos decorrentes na gravidez, visto que esse número se caracteriza por uma parcela de mulheres que se submetem ao exame diagnóstico somente no período gestacional. Além disso, a transmissão vertical (TV) é outro problema, que se agrava, seja pelo parto ou pela prática de amamentação (FERNANDES et al., 2017).

Tendo em vista todo esse cenário de contaminação da população feminina perpetuando ainda sobre gestantes, é preciso que nesse período de vulnerabilidade e reprodução, continuem sendo ofertadas medidas diagnosticas e de controle para as gestantes no período de pré-natal, como testes anti-HIV e o acompanhamento adequado e de qualidade, assegurando-lhes informações sobre a prevenção da transmissão da mãe para o filho (ARCOVERDE et al., 2015).

A Gravidez é um evento que traz repletas sensações para a mulher, seja pela experiência ou pelas consequências que esse evento possibilita. Nessa fase da vida, vários aspectos podem ser considerados de grave risco para essas mulheres, e ser portadora de HIV é um deles. Para as gestantes esse evento assume um significado bem mais forte e preocupante (RAHIM et al., 2017).

Estudar de maneira superficial sobre as implicações causadas pela infecção do HIV em mulheres em fase reprodutiva, desvia o foco dos profissionais para esse problema de saúde pública. É imprescindível que no período de pré-natal não seja feito somente o rastreio da infecção e o acompanhamento, mas também a escuta minuciosa dos sentimentos e experiências novas que esse momento trouxe para a vida dessas mulheres, inclusive esses relatos podem ajudar no manejo dos profissionais (BERTAGNOLI et al., 2017). Neste contexto, surge tal problemática: qual a percepção 
das gestantes sobre o HIV? Quais as principais experiências vividas por elas? De que modo esses fatores refletem na vida das gestantes?

As gestantes HIV-positivo são seres de condição de vida alterada, que também apresentam outras necessidades e particularidades diferentes do que normalmente teriam. Essas pessoas são seres humanos de muitas relações sociais permeadas por outros fatores não apenas biológicos, como também históricos, herança familiar, social, acompanhados por sentimentos como medo, insegurança, sobrecarga, dúvidas a respeito da transmissão vertical, amamentação, autocuidado e o uso de medicação. Portanto, a gravidez é um momento que requer atenção integral e particularizada, para evitar acentuação dessas experiências e obter melhores resultados (SERRÃO et al., 2019).

Partindo desse pressuposto, é imprescindível que mulheres em período gestacional e em situações de infecção pelo HIV, recebam fortalecimento nas relações cliente-profissional. Nesses momentos incluem-se também a tomada de medidas de proteção, ajuda, promoção do auto cuidado e ferramentas para trazer saberes sobre a doença (SERRÃO et al., 2019).

Portanto, estudar sobre essa parcela frágil e vulnerável da sociedade, se torna justificável pelo crescente número de gestantes HIV positivo, que passam por esse problema de saúde pública e que precisam ser assistidas de forma humanizada de acordo com suas experiências, em especial quando elas têm consciência da soropositividade e decidem ter outra gestação.

Portanto, esse estudo teve como objetivo identificar as percepções das gestantes que vivem com o HIV sobre a maternidade e conhecer as expectativas e os sentimentos vivenciados por essas mulheres.

\section{METODOLOGIA}

Trata-se de um estudo descritivo, documental de natureza qualitativa. O local da pesquisa foi o Serviço de Atendimento Especializado (SAE) em HIV/aids do Hospital Regional Materno Infantil (HRMI) de Imperatriz-MA, sudoeste maranhense, maternidade de referência para gestantes de baixo e alto risco e cuidados maternoinfantil da macrorregião, assim atendendo a gestantes HIV-positivo.

Foram incluídas na pesquisa mulheres de qualquer idade, não usuárias de drogas, independente do período gestacional, diagnosticadas com o HIV, atendidas no SAE no 
período de estudo, procedentes de qualquer cidade. Foram excluídas as que tivessem problemas cognitivos ou de linguagem que pudesse dificultar a comunicação com os pesquisadores.

Durante o período de realização da pesquisa, o serviço acompanhava 34 gestantes soropositivas para HIV. A amostra do estudo foi composta por 17 gestantes que apresentavam soropositividade para HIV, acompanhadas pelo serviço no período de realização do estudo. As outras 14, não compareceram às consultas de pré-natal no momento da pesquisa e 3 não aceitaram participar da pesquisa por não se sentirem à vontade para responder as perguntas, o que impossibilitou a coleta de dados dessas gestantes.

A coleta de dados aconteceu de agosto de 2019 a julho de 2020 sendo que devido a pandemia do Covid-19, a partir de março de 2020, os dados de 5 participantes foram coletados através de contato telefônico. $\mathrm{O}$ contato com as participantes aconteceu após as consultas de pré-natal, as mulheres eram convidadas a participar da pesquisa o que aconteceu em sala individual e as entrevistas foram gravadas seguindo formulário elaborado anteriormente pelos pesquisadores e tiveram seus dados coletados do prontuário.

A análise dos dados se deu pela análise de conteúdo proposta por Bardin (2016) dividida em três etapas: pré-análise e exploração do material, tratamento dos resultados e a interpretação. Após a análise e transcrição das falas, caracterizou-se o conteúdo em quatro categorias temáticas: Sentimentos vivenciados frente ao diagnóstico do HIV e perspectivas para o futuro; Sentimentos relacionados a gestação no contexto do HIV; Esperanças e expectativas com o futuro do filho; Sensação de impotência diante da impossibilidade de amamentar.

Seguindo os preceitos éticos o presente estudo foi aprovado pelo Comitê de Ética em Pesquisa da Universidade Federal do Maranhão sob o número do Parecer: 2.496.047.

\section{RESULTADOS}

\section{Caracterização das gestantes}

A caracterização das gestantes mostrou que elas tinham idades entre 17 e 35 anos, sendo que a maioria $(64,7 \%)$ estava na faixa entre 20 e 30 anos. Quanto às demais características, eram pardas, nove viviam com companheiro e oito não; quatro tinham 
menos de 12 anos de estudo; a maioria (76,5\%) era dona de casa e eram procedentes de municípios vizinhos a Imperatriz $(88,2 \%)$. No tocante à história obstétrica, quatro mulheres eram primíparas; treze multíparas; sete tinham história de abortamento anterior a esta gestação; todas faziam pré-natal.

Em relação a percepção das gestantes sobre o HIV, foram direcionadas às gestantes, algumas perguntas objetivas sobre o assunto visando conhecer a percepção das mesmas sobre o tema. 16 delas $(94,1 \%)$ não tinham esse conhecimento ou tinham apenas ouvido falar sobre a doença; tinham conhecimento do preservativo como forma de prevenção para o HIV 14 (82,3\%); nove usavam preservativo como método contraceptivo; 12 conheciam seu diagnóstico antes da atual gestação; todas responderam que desconheciam o que é aleitamento materno exclusivo (AME), e todas faziam uso de Terapia Antirretroviral (TARV); a família conhece o diagnóstico de 15 mulheres $(88,2 \%)$.

Além das experiências das gestantes citadas acima, outros sentimentos, decisões e expectativas foram revelados pelas gestantes a partir do diagnóstico de HIV, como pode ser observado nas falas que foram categorizadas abaixo:

\section{Categoria 1: Sentimentos vivenciados ante o diagnóstico do HIV e perspectivas para o futuro}

Algumas das gestantes apresentaram sentimentos negativos ao tomarem consciência do diagnóstico, o que se observa em suas falas:

Muita tristeza. G3

Sentimento de ódio. G4

Tristeza né, realmente você sente (silenciou), foi assim um baque para mim, nunca imaginei que teria essa doença, então realmente foi uma tristeza para mim. G6

Me senti péssima né, por que é algo pelo resto da vida e é isso que eu penso. $\mathrm{G} 7$

Eu fiquei traumatizada, é muito ruim ser HIV e estar grávida ao mesmo tempo. G8

Eu fiquei muito triste. G10

Tristeza. G12 
Quase entrei em depressão entrei em desespero, mas não cheguei a isso, por que contei para minha mãe e para uma prima minha, e na hora eu pensei que meus sonhos tinham acabado que minha vida tinha sido destruída, e hoje estamos vencendo a cada dia e realizando nossos sonhos. G13

Eu fiquei aterrorizada, por que eu só tinha relação com meu marido então ou ele pegou de mim ou eu peguei dele. G14

No começo eu fiquei triste e chorando, pensei até em fazer besteira mas teve uma amiga que me deu conselho. G15

Senti um pouco de tudo né, medo e desespero, mas graças a Deus enfrentei com coragem. G16

Só fiquei assustada quando descobri. G17

As gestantes acima apresentaram sentimentos como tristeza, mas algumas reagiram de forma exacerbada como preocupação pelo diagnóstico e até mesmo desespero:

Eu fiquei muito para baixo, fiquei muito preocupada, mas, tive muitas orientações do médico lá sobre isso, e é difícil né, tem hora que você esquece, mas tem hora que me lembro disso, eu tenho medo que ele nasça com problema. G2

Nossa, no inicio eu entrei em desespero e eu não entendia muito da doença, e quando meu marido morreu eu imaginei que morreria também, mas eu conheci um médico que me avisou do diagnóstico e de que o HIV com tratamento posso viver absolutamente bem. G5

Deu vontade de me matar não vou mentir, entrei quase em depressão, e eu fico pensando que meu filho vai pegar, mas eu penso que quando se tem Deus né. G11

Para algumas mulheres, a descoberta do diagnóstico não provocou surpresas, como se observa nas falas a seguir:

Nada, (silenciou). Minha mãe até brigava comigo para eu tomar o remédio, por que eu não ligava. G1 
Para falar a verdade não tive muito tempo para pensar direito, foi um tempo muito rápido do período que eu descobri para o nascimento do meu outro filho, então eu não senti nada. G9

\section{Categoria 2: Sentimentos relacionados a gestação no contexto do HIV}

A opção pela gestação é considerada uma das principais decisões reprodutivas que as mulheres tomam, entretanto, na maioria dos casos a gravidez não foi planejada, como se observa nas falas a seguir:

Não vou mentir foi um descuido mesmo. Minha mãe dizia minha filha tu não podes engravidar, mas não adianta mentir né, na virada de ano minhas amigas me chamaram para beber e eu não podia mais ai acabei bebendo e esqueci de tomar remédio. G1

Vacilo mesmo meu, não era para isso ter acontecido porque não foi nada planejado. G2

Não foi planejado, não queria agora queria terminar os estudos, mas, se Deus quis né não posso fazer nada. G3

Não teve nenhum motivo ou vontade não, foi um descuido mesmo. G4

Não foi planejada, e eu não queria essa gravidez, eu me arrependo, não queria, tá difícil para eu aceitar isso. G5

Foi algo que aconteceu, a camisinha estourou, mas sempre tive vontade de ser mãe de novo, mas não tinha coragem de tentar, por que tenho medo da criança pegar a doença. G13

Não foi planejada mulher, eu ainda estava de luto do meu filho e ai aconteceu, acho que eи e meu marido estávamos carentes. G14

Foi uma aventura aconteceu por acaso. G15

Eu não planejei, foi algo que só sentia enjoo e vi minha barriga crescer fiz a ultrassom e vi minha barriga crescer. G17 
Entretanto, em alguns casos as mulheres optaram pela gestação e não mostraram arrependimentos, como apresentado abaixo:

Sim, na verdade a gente sempre sonhou em ter um filho e como a gente estava 2 meses juntos a gente resolveu ter um filho. G6 Não né, meu filho, Deus quis. G7 É porque eu queria ter um filho. G8 Porque toda mulher tem vontade de ser mãe né, e eu já tinha visto no complexo de saúde relatos de mulheres soropositivas para o HIV que engravidaram. G9

Essa gravidez foi planejada. G16

Não porque foi coisa de Deus né. G17

As gestantes foram indagadas ainda como elas encaravam a gestação no contexto do HIV e se tinham algum sentimento de arrependimento pela gravidez. Esses sentimentos foram expressos nas falas:

'Sim, por que como não foi uma coisa planejada, eu fico com muito medo entendeu, a gente confia porque tudo que a gente pede pra Deus ele dá, e eu estou alegre, estou feliz, queria ter uma menina, eu sei do problema que eu tenho mas eu tenho fé em Deus. G1

Sim, porque não foi algo planejado, e eu fico com medo dele ter a doença. $\mathrm{G} 2$

Sim e não né, porque a gente não tem como não fazer o que Deus quer. G3

\section{Categoria 3: Esperanças e expectativas com o futuro do filho}

A temática revela os sentimentos das gestantes soropositivas relacionados à saúde e o futuro dos filhos diante do HIV, como se observa nos depoimentos:

Que ele tenha saúde né. G1 
Eu espero que ele tenha saúde né, tantas coisas acontecendo, e eu tenho medo que ele não tenha saúde, espero que ele esteja bem, como não foi planejada eu fico com medo. G2

Saúde mesmo. G3

Sinceramente ele vai ser entregue para minha irmã, mas eu espero que ela tenha muita saúde. G4

Eu espero que ele tenha saúde, eu fico com medo, até eu saber que ele vai nascer sem a doença, eu fico muito angustiada, com medo, G5

Assim, em relação a saúde dele, que ele venha nascer sem esse problema, além de correr o risco, o médico também já explicou que com tratamento certo pode ser que ele não tenha, então a saúde dele é mais importante. G6

Que venha com saúde né, essa gravidez é importante mesmo com essa doença. G7

Eu espero coisas boas para ele. G8

Eu espero que ele nasça sadio (risos). G9

Uma vida normal. G10

Que ele não tenha a doença. G11

Eu espero coisas boas, que ele tenha saúde, não tenha a doença e eu estou lutando pra isso, tomando meus remédios e tendo uma boa alimentação. G13

Eu desejo tudo de bom para ele, saúde e estou lutando para isso. G14

Espero que ela tenha o melhor, dou tudo pela minha filha. G15

Que venha com saúde, o principal é a saúde e que ele não tenha a doença. G16

Eu quero que Deus traga ele com muita saúde. G17

\section{Categoria 4: Sensação de impotência diante da impossibilidade de amamentar}

A representação da maternidade está intimamente ligada ao ato de amamentar. A impossibilidade de amamentar no contexto do HIV pode ser visto nas falas a seguir, por mais deficiente que fosse o conhecimento sobre o tema: 
Devido o problema que eu tenho né, eu sei que não posso, então eu sinto que é um amor longe, eu brigo muito com meu outro filho, mas não é por que eu não gosto dele, mas parece que é assim porque ele não mamou é vai ser assim com esse. G1

Eu penso que como eu já imaginava isso, já escutava isso de outras pessoas, isso é ruim né, até porque eu já amamentei meu outro filho, e eu sei o quanto isso é ruim, e a importância que tem. G2

Triste né, fazer o que? G3

É ruim. G4

Eu digo até que é um alivio, quando eu amamentei meu outro filho criou ferida no meu peito, ciou tudo de ruim, eu fico triste porque é uma saúde a mais para o bebê, mas dizer que é lindo amamentar não é, é um alivio para mim, por causa de dor e feridas. G5

Assim, como eu já sabia antes realmente é muito difícil para o bebê, e o leite materno é o principal, e é uma tristeza maior ainda porque toda mãe quer ter seu filho, quer amamentar seu filho e ter os cuidados. G6

Normal porque os outros não mamaram também, mas eu reconheço que é importante só que eles nunca mamaram por vontade deles, e não porque eu não quis. G7

É ruim, porque tem que amamentar o bebê pelo leite do peito porque é importante. G8

Ruim né, é uma má sensação. G10

É triste né. G11

Eu sinto um vazio, porque como eu já tive a sensação de engravidar, nessa eu sinto a sensação que fosse falta de alguma coisa para o crescimento do meu bebê. G13

Eu não sinto nada não, mas eu nunca amamentei tinha até vontade, mas depois dessa doença deixei para lá. G14 
Muito triste a gente ver nossa filha chorar, e não poder fazer nada, quero ir para casa dar a comida para ela. G15

Com o outro filho que eu tive, eu já tinha a doença então foi difícil, só não foi mais difícil porque eu não tinha leite no peito. G16 É triste saber que não posso amamentar meu filho. G17

\section{DISCUSSÃO}

Os resultados corroboram os resultados de outra pesquisa ao identificar que as gestantes que vivem com o HIV estão na faixa etária entre 20 e 30 anos período que compreende uma fase em que as mulheres estão em idade reprodutiva (CAMPOS, 2020), são negras ou pardas população predominante no norte e nordeste do Brasil e concomitante a isso é uma população de maior risco e vulnerabilidade, de forma que merecem uma maior atenção em seu acompanhamento de saúde (SILVA et al., 2015).

Observou-se que as mulheres tinham um companheiro, como em pesquisa realizada no interior do Pará (NASCIMENTO et al., 2018). A companhia do parceiro é importante nesse período de adoecimento e reprodução para que a mulher se sinta segura nesse momento difícil, sendo uma ajuda na tomada de decisões e apoio (LIMA et al., 2017).

No presente estudo a maioria das mulheres eram donas de casa. Tais achados corroboram com a possibilidade de que as mulheres com menos escolaridade têm dificuldades de ingresso no mercado de trabalho e tanto a escolaridade como a situação laboral são de importância quando se refere a dados socioeconômicos (NASCIMENTO et al., 2018). Uma maior escolaridade pode ser vista de forma positiva, pois mais instrução melhora seu entendimento sobre a doença e informações pertinentes ao seu estado de saúde (SOUSA et al., 2015).

Em relação à procedência das gestantes do estudo, $88,23 \%$ eram de outras cidades, porém faziam o pré-natal na cidade em que sedia o hospital de referência. Há necessidade de se fazer um planejamento e organização de atenção em saúde voltada para essas mulheres, bem como o oferecimento de um atendimento de qualidade que possibilite o alcance melhor dessas mulheres ao serviço oferecido (LIMA et al., 2017). 
O número de gestações entre mulheres HIV positivo vem aumentando (CAMPOS, 2020). Dados do Ministério da Saúde apontam que uma parcela considerável dos diagnósticos de casos da doença se dá durante o período gestacional, refletindo a adequação da política de saúde na atenção pré-natal (BRASIL, 2017).

A ocorrência de abortos entre as mulheres do presente estudo foi de 41,17\%. O abortamento é uma das complicações mais recorrentes em gestantes, situação que merece atenção, pois existe uma importante relação entre doenças sexualmente transmissíveis e abortamento (ARAÚJO et al., 2018). Isso demonstra que gestantes HIV positivo precisam de atenção à saúde de qualidade.

Sabe-se que boa parte de mulheres gestantes HIV positivo descobrem sua soropositividade antes da gravidez que é de certa forma positivo, pois mulheres que tiveram outras gestações tiverem a oportunidade de serem testadas precocemente. Mas é válido ressaltar que ainda há taxas consideráveis de gestantes que não conhecem seu status sorológico, seja por desconhecer a possibilidade de testagem, seja por deficiência do pré-natal que não oferece esse resultado (CAMPOS, 2020).

Em situações em que o diagnóstico de HIV positivo aconteça durante a gestação ou no pós-parto pode desencadear pensamentos variados, algumas dúvidas, o que pode trazer impactos à vida dessa mulher e a do bebê (SILVA et al., 2018). A realização do pré-natal em gestantes é um fator relevante na medida em que é nesse momento em que são ofertados os testes para HIV e acompanhamento das mulheres, havendo a possibilidade da descoberta do diagnóstico de HIV positivo precocemente possibilitando seu acompanhamento (CAMPOS, 2020).

O período gestacional é um momento permeado de mudanças sendo elas hormonais quanto do sistema imunológico da gestante evolvida no processo, por isso nesse período a mulher está predisposta ao adoecimento por IST/HIV (ARAÚJO et al., 2018). É necessário que nesse período, a mulher adquira conhecimentos relacionados ao HIV, envolvendo questões omissas que as levem a situações de vulnerabilidade. Atualmente, esse assunto tem ganhado cada vez mais proporções significativas nos meios de comunicação, proporcionando um maior conhecimento sobre o HIV. Porém ainda existem muitas pessoas desfavorecidas, com fatores que interferem nesse conhecimento, sendo elas socialmente e economicamente desprivilegiadas, e por isso conhecer sobre uma doença ajuda a identificar medidas de prevenção (JORDÃO et al., 2016). 
Há muitas mulheres que conhecem a utilização do preservativo, porém não aderem, isso pode ser hipoteticamente caracterizado como um problema de negociação dos parceiros homens com as mulheres na prática do sexo seguro, revelando um cenário de desigualdade e inferiorização do sexo sobre o outro. Isso repercute negativamente sobre as mulheres que são as únicas responsáveis pela concepção, e acabam não defendendo seus direitos sexuais e reprodutivos em sua plenitude, vivendo de maneira desigual. Além do mais, vale ressaltar que mulheres HIV positivo também podem contrair outras doenças sexualmente transmissíveis (ASSIS et al., 2016).

A fim de evitar a contaminação de mulheres pelo HIV, o pré-natal compreende um momento de fazer diagnósticos, como também fazer tratamento precoce, e evitar a transmissão vertical em mulheres gestantes HIV positivo e reforçar a testagem anti-HIV (VIEIRA, 2016).

Diante desse cenário de contaminação das gestantes pelo HIV, logo emerge outra questão bastante relevante relacionada com a saúde da criança que essas mulheres estão gerando, entre elas, está o aleitamaento materno. O Ministério da Saúde (MS) recomenda que todas as crianças sejam beneficiadas pelo aleitamento materno exclusivo (AME) durante os primeiros seis meses de vida, podendo ser complementado e se estender até por dois anos de idade ou mais (CRISTOFARI et al., 2019).

Apesar dos benefícios do AME, a mulher HIV positivo não deve amamentar, de forma que destaca-se a importância da assistência de enfermagem para promover educação em saúde sobre esse assunto tão importante para as gestantes. Essa assistência visa favorecer o esclarecimento de dúvidas pertinentes, e incentivo do auto cuidado (CRISTOFARI et al., 2019).

Falando na saúde da criança e os riscos da transmissão vertical (TV) tem se tornado cada vez mais importante, visto que a falta de um cuidado minucioso podem aumentar essas taxas (ARRUDA et al., 2016). Evitar casos de contaminação de crianças pelo HIV é necessário e requer a participação das mães na tomada de medidas profiláticas e dos profissionais com informações e a adoção da profilaxia que possa evitar a TV (ARRUDA et al., 2016).

O fato de que as mães e os profissionais de saúde dão prioridade em salvar o bebê, centralizando assuntos como profilaxia contra a TV e toda medicação envolvida, coloca as mulheres como se fossem o foco de "risco" para a criança. De certa forma 
essa recarga de responsabilidades acentua os medos dessas mulheres (BELLOTTO et al., 2019).

A falta de informação sobre o HIV, e as representações sociais que ela tem, enriquece esse sentimento de medo, insegurança, bem como a ideia de possibilidade de morte, que está bem ultrapassada nos dias de hoje. Como também, a infecção pelo HIV representa para as mulheres muitos resultados negativos, que querendo ou não são atreladas a diversas outras dificuldades. Um desses fatores que podem acentuar esse sofrimento é ter que lidar com o tratamento que envolve o uso de terapia antirretroviral (TARV) (RAHIM et al., 2017).

O tratamento para o HIV consiste no uso de medicamentos antirretrovirais, disponibilizados pelo SUS gratuitamente. Ainda não existe cura para o HIV, porém a adesão a esse tratamento proporciona uma melhor qualidade de vida a essas pessoas. Quanto mais precocemente for tratado, menor serão as chances de evolução para a aids. Hoje, a adesão a esse tratamento é bem maior do que antes, pois os medicamentos apresentam efeitos colaterais, não tão acentuados como as fórmulas antigas. A adesão ao tratamento do HIV compreende tomar a TARV de forma correta e continua. Se não utilizados de forma correta perde sua eficácia no organismo ganhando resistência. Por isso, é importante que os profissionais que acompanham esses pacientes, reforcem a boa adesão ao tratamento e sua eficácia (BRASIL, 2015).

Portanto, a adesão é fundamental o quanto antes nesse período, para que as gestantes se tratem e possam cuidar dos seus filhos (GONÇALVES et al., 2019). A preocupação das mães com os filhos, a priorização da TARV deve ser a motivação nesse período ante a possibilidade de que a criança não tenha a doença. Percebe-se então a sensibilização do emocional das mães, que as fazem seguir rigorosamente o tratamento a partir dos seus diagnósticos (BELLOTTO et al., 2019)

Entretanto, há alguns fatores que podem ser apontados como motivo do abandono da TARV, que pode ser a falta de sinais e sintomas da doença, falta de alguns efeitos colaterais, mais uma vez a desinformação da doença pode ser um problema nessa questão, fazendo com que elas desistam de continuar com o tratamento. Nesse contexto, a ajuda de profissionais da saúde que atuam de forma interdisciplinar pode ser ímpar nessa adesão (RAHIM et al., 2017).

A família representa núcleo e base para todas as pessoas, e é o alicerce da sociedade, é nela que as pessoas nascem, crescem e se desenvolvem. Diversos estudos 
demonstram que a participação do pai, dos avós maternos e paternos auxilia a mulher nesse processo, e ajuda na rede psicológica de cuidados a essa gestante. Ainda existe muita discriminação na família que se estende por toda sociedade, esses estigmas trazem muitas injustiças e reforçam os velhos estigmas já existentes (MEDEIROS et al., 2019).

A revelação diagnóstica do HIV positivo para a família, representa um apoio a mais, ajuda no cuidado, e nas tomadas de decisão, e a esperança de poder confiar nos familiares. Entretanto, muitas gestantes preferem omitir da família o seu diagnóstico (BRINGEL et al., 2015).

Para muitas gestantes, a dificuldade de enfrentar o diagnóstico pode ser algo extremamente difícil, mas esse momento se torna ainda mais complexo quando não se tem o apoio da família e/ou do parceiro, essa aceitação ou não da família pode interferir positiva ou negativamente no processo de tratamento e aceitação do HIV positivo. A família pode ajudar na adesão de todas as medidas profiláticas referentes a seu diagnóstico, e o distanciamento familiar pode dificultar esse processo (FERNANDES et al., 2017).

Anteriormente, o HIV/aids era associado a gays, travestis e prostitutas, tirando a visibilidade da infecção pelas mulheres, até por que ainda perpetuam as questões sociais e morais da sociedade, onde tem o casamento como ideal de proteção a contração de doenças como HIV. A não associação das mulheres aos grupos de "risco", faz com que a percepção de cuidados, a procura da testagem e tomada de medidas de prevenção, estabeleça um cenário de contaminação despercebida dessas mulheres que sim, são vulneráveis, e ainda em período de reprodução (CARVALHO et al., 2019).

A vivência com o HIV implica as mulheres apresentarem diversos sentimentos que decorrem do emocional ao enfrentar o vírus. Esses sentimentos fazem com que as gestantes tenham dificuldades em esquecer esse diagnóstico, visto que o papel que elas assumem na sociedade, é de mulheres que protegem e, que não podem parecer um risco (MEDEIROS et al., 2015).

Momentos como este de gestação somado a infecção pelo HIV, proporciona eventos diferentes entre viver e morrer, que começa a fazer parte da vida dessas mulheres, sentimentos esses que são vistos como válvula de escape para certas situações difíceis, mesmo que morrer não seja visto como algo bom, pelo contrário, muito 
intimidador. Torna-se indispensável frisar que, sentimento de ódio revela um sentimento de culpa pela infecção (MEDEIROS et al., 2015).

A revelação do diagnóstico de HIV em gestantes, provocando todos esses sentimentos, faz com que ao longo do processo gestacional, essas angústias perdurem para além da gestação, até o puerpério. Por isso, a importância de uma assistência de qualidade a essas mulheres, que vá além de questões clinicas obstétricas desencadeadas pelo diagnóstico. É possível também presumir que mulheres nessas condições de não aceitação do HIV, são mulheres que nunca se permitiram pensar na possibilidade de adoecimento por uma doença sexualmente transmissível, questões religiosas, sociais que previamente adquiridas, fazem-nas pensar que não são boas mulheres, o que acentua os sentimentos negativos (FERNANDES et al., 2017).

Declarações como "fé em Deus", é alvo de escape para mais situações difíceis para todas as pessoas em situações complicadas. E para gestantes em situação de serem HIV positivo não seria diferente, o apego a entidades religiosas é também uma forma de aceitar o HIV em momento de reprodução. Além do diagnóstico, aspectos religiosos ajudam no apoio emocional, convivência com a gestante, aceitação familiar e social (BRINGEL et al., 2015).

Outros fatores que proporcionam e acentuam os sentimentos dessas gestantes é o fato de não terem planejado a gravidez. Toda gravidez que contrapõe as vontades do casal, e vai contra as suas expectativas podem ser consideradas indesejadas. Pode ser também considerada inoportuna quando vem em momentos considerados desfavoráveis. Nesse contexto entra a questão do planejamento familiar, que segundo o Ministério da Saúde ressalta que casais têm os seus direitos reprodutivos assegurados, podendo escolher entre ter filhos ou não (EVANGELISTA et al., 2015).

Todos esses direitos devem ser pensados em estratégias como disponibilização de testes anti-HIV, planejamento familiar, o aconselhamento materno, adesão ao tratamento e prevenir a transmissão vertical. Ser HIV positivo não significa estar impossibilitada de engravidar e seguir uma vida como de outras pessoas saudáveis, mas as decisões devem ser baseadas na ajuda das equipes de saúde. Por esse motivo, a equipe de saúde é de fundamental importância na implementação dessas condutas, as decisões de engravidar e transmissão devem ser colocadas lado a lado, respeitando a autonomia da mulher (SOUZA, 2016). 
O medo da criança futuramente ser doente, se explica pelo HIV ser uma doença incurável, e mesmo seguindo o tratamento corretamente ainda restam essas dúvidas, fazendo com que as pessoas expressem sentimentos e expectativas relacionadas ao futuro da criança (HERNANDES et al., 2019).

Outro aspecto é a confiança nos resultados negativos do filho, mesmo quando ainda sendo feto, a mãe se sente na responsabilidade de cuidar de si mesma, tomar os cuidados necessários, fazendo com que tenham confiança na saúde futura do seu filho, e satisfação do papel materno (BRINGEL et al., 2015).

Quando se fala em gestação, surge o tema muito discutido que é a amamentação. Porém, as medidas profiláticas de reduzir a transmissão do HIV para a criança pela TV inclui a exclusão da amamentação reduzindo em $20 \%$ a possibilidade de transmissão da doença para o filho, um dos maiores objetivos da saúde pública é voltada a evitar essa problemática (BRASIL, 2015).

Para mulheres que já tem uma experiência prévia de amamentação de seus filhos em gestações anteriores, sentem que a falta dessa prática pode representar falta de amor, a falta de competência de fazer o que toda mãe deve fazer, que é amamentar. A ausência desse ato pode desencadear nas mulheres sentimento de tristeza, de algo ruim. A nova fase de não poder amamentar o filho, passa uma desconstrução do simbolismo materno que é amamentar. Esse simbolismo já está arraigado nas construções sociais, e a não possibilidade de realiza-lo faz com que a mulher se sinta incapaz, e surge um cenário de utilização de artifícios para substitui-los como o uso de mamadeiras e outros. É notório o sofrimento das gestantes diante desse cenário, e assim é preciso cuidar também da saúde física e psíquica das mulheres (PAULA et al., 2015).

Como o aleitamento materno é preconizado pelo Ministério da Saúde por fortalecer os laços afetivos de mãe e filho, as gestantes devem receber apoio profissional e serem bem orientadas sobre os motivos dessas decisões para evitar as frustrações. A não amamentação pode representar um distanciamento do binômio, mãe e filho e futuramente pensarem que pode ser um relacionamento interrompido irreversível (HERNANDES et al., 2019).

\section{CONSIDERAÇÕES FINAIS}


Verificou-se que a percepção das gestantes HIV positivo sobre essa doença, demonstrando uma visão do quanto o conhecimento sobre esse tema reflete de alguma forma no seu modo de vida, e a forma de encarar a realidade. A partir de então, foi observado que as gestantes apresentam pouco conhecimento em relação ao HIV, e relacionado a isso uma vasta carga de sentimentos negativos ocasionados pela situação.

Foi possível perceber que a expectativa dessas mulheres é que consigam ter saúde e que seus filhos nasçam sem a doença. Sentimentos esses naturais ao saberem que podem ser uma fonte de transmissão para seus filhos. A importância que a equipe multidisciplinar tem nesse processo de adaptação da gestante na sua nova realidade, principalmente no momento de pré-natal é crucial. Além disso, os profissionais devem estar sempre atentos não só no processo saúde-doença física, como também na saúde mental, pois esses danos psicológicos que podem ser causados.

Tornou-se crucial averiguar sobre a expectativa que as mães tiveram em relação a seus filhos, pois essa análise pode de certa forma ajudar as mãe a terem uma boa conduta durante seu período de gravidez. Além disso, é indispensável que mesmo em ambiente hospitalar os profissionais realizem ações educativas em saúde, para que as mulheres conheçam detalhes sobre a sua doença bem como sobre a transmissão vertical. Algumas mães tinham pouco conhecimento sobre a impossibilidade da não amamentação de seus filhos, demonstrando tristeza sobre a situação, visto que podiam estar expondo seu filho com esse ato.

A pesquisa teve algumas limitações em relação a ausência de algumas gestantes nas consultas. Algumas mulheres no momento da entrevista se demonstraram muito tímidas na hora de responder algumas perguntas, porém foi possível coletar informações necessárias.

\section{Agradecimentos:}

A Universidade Federal do Maranhão. PIBIC/CNPq/FAPEMA/UFMA 2019-2020 EDITAL PPPGI No $13 / 2019$

Este estudo foi financiado pela Coordenação de Aperfeiçoamento de Pessoal de Nível Superior - Brasil (CAPES) - Finance Code 001

\section{REFERÊNCIAS}

ARCOVERDE.M.A.M, et al. Sentimentos e expectativas da gestante vivendo com HIV: um estudo fenomenológico. Revista Mineira de enfermagem (REME), v. 9, n. 3, p. 554-560, 2015. DOI: http://www.dx.doi.org/10.5935/1415-2762.20150043 
ARRUDA.S.F.A, et al. Desvelando o conhecimento de gestantes soropositivas acerca da transmissão vertical do HIV. Revista de enfermagem UFPE On line, v. 10, n. supl.3, p. 1441-1449, 2016. https://pesquisa.bvsalud.org/portal/resource/pt/biblio1031806

ASSIS, M.R, et al. Conhecimento e prática sexual de gestantes HIV positivas atendidas em hospital universitário. Revista de Enfermagem UERJ, v. 24, n. 6, 2016. https://go.gale.com/ps/i.do?id=GALE\%7CA568569346\&sid=googleScholar\&v=2.1\&it $=\mathrm{r} \&$ linkaccess $=\mathrm{abs} \& \mathrm{iss}=01043552 \& \mathrm{p}=\mathrm{IFME} \& \mathrm{sw}=\mathrm{w} \&$ userGroupName $=\mathrm{anon} \% 7 \mathrm{Ea} 49$ e48c4

BARDIN, Laurence. Análise de conteúdo. $7^{\circ}$ edição. Pág 74. Editora Almedina Brasil. Abril. São Paulo. 2016.

BELLOTTO, P.C.B, et al. Entre a mulher e a salvação do bebê: experiências de parto de mulheres com HIV. INTERFACE, comunicação, saúde, educação, v. 23, n. 57, p. 115, 2019. https://doi.org/10.1590/Interface.180556

BERTAGNOLI, M.S.F.F, et al. Gestantes Soropositivas ao HIV: Maternidade, Relações Conjugais e Ações da Psicologia. Psicologia: Ciência e Profissão, v. 35, n. 4, p. 981994, 2017. https://doi.org/10.1590/1982-3703004522016

BRASIL. Ministério da Saúde. Cuidado integral ás pessoas que vivem com HIV pela Atenção Básica. Manual para a equipe multiprofissional. Brasília (DF). $1^{\circ}$ edição. 2015.

file://C:/Users/Flor/AppData/Local/Temp/cartilha_cuidado_integral_02_2016_pdf_122 77-1.pdf

BRASIL. Ministério da Saúde (Br), Secretaria de Vigilância em Saúde, Departamento de Vigilância, Prevenção e Controle das Infecções Sexualmente Transmissíveis, do HIV/Aids e das Hepatites Virais. Bol Epidemiol HIV AIDS, v. 5, n. 1, p. 1-60, 2017. file:///C:/Users/Flor/AppData/Local/Temp/boletim_aids_internet-1.pdf

BRINGEL, A.P.V, et al. Vivência de mulheres diagnosticadas com HIV/AIDS durante a gestação. Ciência cuidado saúde, v. 14, n. 2, p. 1043 - 1050, 2015. DOI:

https://doi.org/10.4025/cienccuidsaude.v14i2.22299

CAMPOS, D. P. Perfil epidemiológico de gestantes com HIV positivo e a transmissão vertical em um hospital municipal de Niterói. Saúde coletiva, v. 10, n. 52, p. 22802287, 2020. DOI: 10.36489/saudecoletiva.2020v10i52p2280-2295

CARVALHO, J.M.R. Experiências e Perspectivas de Mulheres Vivendo com HIV/aids sobre Direitos Sexuais e Reprodutivos. 2019. 133 f. Dissertação (Mestrado em Saúde Pública - Escola Nacional de Saúde Pública Sergio Arouca. Fundação Oswaldo Cruz, Rio de Janeiro - RJ, 2019.

https://www.arca.fiocruz.br/handle/icict/34179

CRISTOFARI, R.C, et al. Conhecimento acerca do aleitamento materno de gestantes atendidas na atenção básica de saúde. Revista Brasileira em Promoção da Saúde, v. 32, n. 9558, p. 1-15, 2019. DOI: https://doi.org/10.5020/18061230.2019.9558 
EVANGELISTA, C.B, et al. Gravidez não planejada e fatores associados á participação em programa de planejamento familiar. Revista de Pesquisa Cuidado é Fundamental Online, v. 7, n. 2, p. 2464-247, 2015.

https://www.redalyc.org/articulo.oa?id=505750946023

FERNANDES, P.K.R.S, et al. Revelação diagnóstica para o HIV no pré-natal: dificuldades e estratégias de enfrentamento das mulheres. Revista de Enfermagem UERJ, v. 25, n. e12114, p. 1-5, 2017.

DOI: http://dx.doi.org/10.12957/reuerj.2017.12114

GONÇALVES, C. T., et al. A relevância do uso da TARV na prevenção da transmissão vertical do HIV. A relevância do uso da TARV na prevenção da transmissão vertical do HIV. Revista Caderno de Medicina, V. 2, N. 2, P. 71-78, 2019. file:///C:/Users/Flor/AppData/Local/Temp/1404-5451-1-PB-2.pdf

HERNANDES, C.P., et al. Análise qualitativa dos sentimentos e conhecimentos acerca da gestação e do HIV em gestantes soropositivas e soronegativas. J. Health Biol Sc v.7,n. 1, p 32-40, 2019.

DOI: http://dx.doi.org/10.12662/2317-3076jhbs.v7i1.2211.p32-40.2019

JORDÃO, B.A, et al. Conhecimento da gestante sobre o HIV e a transmissão vertical em São José do Rio Preto, São Paulo, Brasil. Revista Brasileira de Pesquisa em Saúde, v. 18, n. 2, p. 26-34, 2016.

https://periodicos.ufes.br/rbps/article/view/15081

LIMA, S.K.S.S, et al. Caracterização das gestantes com HIV/AIDS admitidas em hospital de referência. Revista de politicas públicas (SANARE), v. 16, n. 1, p. 45-51, 2017. file:///C:/Users/Flor/AppData/Local/Temp/1093-2642-1-SM-2.pdf

MEDEIROS, A.P.D.S, et al. A experiência da soropositividade para grávidas com HIV/AIDS: preconceito, dor, trauma e sofrimento pela descoberta. Revista de Enfermagem UERJ, v. 23, n. 3, p. 362-366, 2015.

MERLEAU-PONTY, M. Fenomenologia da percepção. São Paulo: Martins Fontes; 1999.

NASCIMENTO, V.B, et al. Aspectos epidemiológico e clinico de gestantes com HIV/AIDS atendidas em centro de referência em saúde da mulher do município de Santarém, Pará, Brasil. J Health Sci Inst, v. 36, n. 2, p. 109-114, 2018. https://repositorio.unip.br/journal-of-the-health-sciences-institute-revista-do-institutode-ciencias-da-saude/aspectos-epidemiologico-e-clinico-de-gestantes-com-hiv-aidsatendidas-em-um-centro-de-referencia-em-saude-da-mulher-do-municipio-de-santarempara-brasil/

PAULA, M.G, et al. Enfrentamento de puérperas HIV positivas relacionado ao ato de não amamentar. Revista Eletrônica de Enfermagem, v. 17,n. 1, p. 136-142, 2015. DOI: https://doi.org/10.5216/ree.v17i1.23949 
RAHIM, S.H, et al. Gestantes e puérperas soropositivas para o HIV e suas interfaces de cuidado. Revista de Enfermagem UFPE On Line, v. 11, n. Supl. 10, p. 4056-64, 2017. DOI: 10.5205/reuol.10712-95194-3-SM.1110sup201707

SERRÃO, J.R.M, et al. Saberes de gestantes com HIV sobre o autocuidado. Revista $\begin{array}{lllllll}\text { Eletrônica Acervo Saúde, } & \text { v. } 36, \quad \text { n. } & \text { p. } & 1-8, & \end{array}$ file://C:/Users/Flor/AppData/Local/Temp/1563-Artigo-16187-1-10-20191108-1.pdf

SOUZA,C.P, et al. Incidência de transmissão vertical de hiv entre gestantes soropositivas cadastradas em um serviço de referência regional. Revista de Pesquisa Cuidado é Fundamental Online, v. 8, n. 2, p. 4526-4537, 2016.

https://doi.org/10.9789/2175-5361.2016.v8i2.4526-4537

SILVA, M.G, et al. O perfil epidemiológico de gestantes atendidas nas unidades básicas de saúde de Gurupi, Tocantins. Ciências da saúde, v. 13, n. 02. P. 93-102, 2015. http://repositorio.bc.ufg.br/handle/ri/15267

SOUSA, S.F.D, et al. Perfil de gestantes com HIV assistidas na policlínica de GurupiTO. Revista CEREUS, v. 7, n. 03, p. 163-175,. 2015. http://dx.doi.org/10.18605/21757275/cereus.v7n3p163-175

VIEIRA, RB.R. Perfil do conhecimento/percepção de HIV/AIDS entre gestantes. 2016. 68 f. Dissertação (mestrado) - Universidade Católica de Santos, Santos, 2016. http://ojs.unirg.edu.br/index.php/1/index 